\title{
PERANCANGAN TELEMETRI AKTIVITAS GUNUNG BERAPI MENGGUNAKAN SENSOR SEISMIK 3C DENGAN GELOMBANG WIFI 2.4GHz
}

\author{
Chotib Alwan ${ }^{1}$, Achfas Zacoeb ${ }^{2}$, D. J Djoko H. Santjojo ${ }^{3}$, Didik R. Santoso ${ }^{3}$ \\ ${ }^{1}$ Mahasiswa/Program Magister Teknik Elektro/FT Universitas Brawijaya \\ ${ }^{2}$ Dosen/Jurusan Teknik Sipil/FT Universitas Brawijaya \\ ${ }^{3}$ Dosen/Jurusan Fisika/FMIPA Universitas Brawijaya \\ J1. MT Haryono 167, Malang 65145, Indonesia \\ Korespondensi:chotibalwan@gmail.com
}

\begin{abstract}
Remote monitoring using high-frequency Wifi telemetry communications media is a solution that enables to benefits from data transfer speed, remote communication, data security system and uses less energy. This study aims to establish a telemetry communication system of integrated sensor networks for the volcanic geographic area with some advantages such as the physical parameters of a volcano conditions accurately in real-time and online, the higher transmission speed, easily duplicated, and the flexibility for additional high sensors as a part of the decision making to determine the volcano status. Wifi telemetry $2.4 \mathrm{GHz}$ offers a high data transfer speed, the current supported equipment or modules have been reached a speed of 100Mbps. Range coverage's performed on this test reached a maximum distance of $2 \mathrm{~km}$ line of sight, the data in the form of sensor data and moving images. The visual data expected is not in fully real-time, because there are 5 seconds delays from the production time. To use a shorter delay in order to the image goes faster, the main processor of raspberry experienced some over heat, and then it is not suitable for a long-term continuous use.
\end{abstract}

Keywords : Access Point, Raspberry Pi, Seismic Sensor, Telemetry, Wifi

\section{PENDAHULUAN}

Gempa vulkanik adalah jenis gempa yang terjadi karena aktivitas magma di perut bumi. Gempa ini tergolong gempa yang cukup intensif terjadi di kepulauan Indonesia yang memiliki banyak gunung berapi. Setiap adanya letusan gunung berapi pasti sebelumnya terjadi getaran yang di rasakan oleh masyarakat sekitar gunung tersebut. Gempa inilah yang dimaksud dengan gempa vulkanik, contoh gempa yang terjadi di daerah gunung Kelud sebelum meletus.

Pemantauan aktivitas gunung berapi dapat dilakukan dengan melihat atau memonitor beberapa perilaku fisik sebagai parameter tanda akan adanya letusan. Salah satu yang dapat di monitoring adalah aktivitas seismik atau getaran diser gunung berapi. Dari aktivitas seismik yang terpantau secara real time ini akan bisa dilakukan monitoring dari jarak jauh dengan sebuah sistem komunikasi atau telemetri, untuk selanjutnya dapat di gunakan sebagai salah satu parameter penunjang keputusan status dari sebuah gunung berapi (Maryanto dkk, 2011).

Selama ini instrumen komunikasi yang digunakan sebagai monitoring adalah menggunakan telemetri analog dengan radio modem, tetapi sistem komunikasi dengan telemetri radio modem memiliki beberapa kelemahan. WSN yang digunakan berbasis radio modem analog dibentuk dalam sebuah jaringan multihop, yaitu terdiri dari node-node yang berkomunikasi dengan nodelain melalui sebuah node tertentu atau node relay. Dengan cara ini maka tidak memungkinkan komunikasi secara langsung dengan pos sentral karena terkendala jarak dan kondisi geografis pegunungan. Gunung akan menjadi semacam obstacle/penghalang yang sangat besar untuk sistem komunikasi (Santoso dkk, 2012a). 
Fokus dalam penelitian ini adalah bagaimana mengembangkan sebuah instrument komunikasi jarak jauh untuk WSN seismik dengan jangkauan yang luas dan dalam kecepatan tinggi untuk mendukung sistem monitoring sensor atau jaringan sensor terpadu yang mampu memberikan informasi secara terpadu, akurat real time dan online, murah, hemat energi dan dengan standar keamanan yang tinggi, dan juga mudah duplikasi.

\section{LANDASAN TEORI}

\subsection{Sensor seismik WSN}

Sensor-sensor ini dapat berdiri sendiri secara tunggal (seperti seismometer atau tilt sensor) maupun dapat dalam membentuk jaringan sensor yang dihubungkan dengan kabel. Jarak antar sensor biasanya dekat, dan dapat saja diintegrasikan dengan jaringan yang besar yang dihubungkan secara point-to-point (Scarpa \& Tiling, 1996).

Perekaman data seismik dilakukan secara periodik atau dipicu oleh kejadian seismik. Data yang direkam disimpan secara lokal, sehingga harus diambil secara periodik atau dikirimkan melalui saluran telepon atau komunikasi radio jarak jauh ke pos pemantauan (Santoso dkk, 2012 ${ }^{\mathrm{b}}$ ).

\subsection{Akses point to multipoint}

Secara garis besar, frekuensi dan perhitungan power pada jaringan point-tomultipoint hampir sama dengan point-to-point. Hanya saja jaringan point-to-multipoint ada yang mampu membentuk jaringan yang baik walaupun di antaranya terdapat penghalang $($ NLOS = Not Line of Sight $)$.

\subsection{Modul MMA7631 untuk Arduino}

Arduino merupakan pilihan yang tepat untuk membaca modul sensor MMA7361. Karena selain dapat melakukan pengaturan secara digital pin kontrol sensor, Arduino juga dapat membaca nilai tegangan analog keluaran sumbu X, sumbu Y, dan sumbu Z. Hasil pembacaan tegangan analog dari tiap sumbu tersebut kemudian dikonversi menjadi nilai digital melalui fitur ADC yang terdapat pada Arduino.

\subsection{Raspberry Pi}

Raspberry Pi dapat dihubungkan dengan sensor kamera, yang dapat digunakan untuk mengambil gambar. Sistem ini juga memiliki port General Purpose Input Output (GPIO) yang dapat digunakan untuk berkomunikasi dengan Arduino.

\section{METODE PENELITIAN}

Fokus masalah yang diambil dalam penelitian ini adalah desain perangkat keras komunikasi nya. Masalah media komunikasi merupakan bagian penting yang harus di selesaikan. Pada penelitian sebelumnya, proses pengiriman dan penerimaan data digital menggunakan media/carrier gelombang radio pada frekuensi $433 \mathrm{MHz}$ menggunakan modul RLP TLP 433MHz. Pada frekuensi ini, data yang dikirimkan tentu saja tidak bisa dalam kapasitas besar. Data visual berupa gambar bergerak tidak dapat diikutkan, karena bandwidth yang sempit dan juga kecepatan transmisi yang tidak seimbang dengan transmisi data pada modul raspberry di bagian node sensor. Pada node sensor sebenarnya sudah bisa didapatkan cukup banyak data dalam kapasitas besar dan transfer rate yang tinggi, tetapi media pembawanya tidak memungkinkan untuk menyampaikannya ke sisi penerima.

Masalah pada pemakaian gelombang radio frekuensi $433 \mathrm{MHz}$ adalah selain ketidakseimbangan antara besar data dan kecepatan transfer data antara pengirim dan media pembawanya adalah kemampuan gelombang frekuensi rendah untuk menembus halangan. Jika pada kondisi Line of Sight, hal ini tidak akan menjadi masalah. Masalah pada penelitian ini adalah karena penelitian ini ditujukan untuk penggunaan di gunung yang tentunya memiliki kondisi geografis yang tidak memenuhi persyaratan Line of Sight, banyak obstacle/penghalang, misal berupa pepohonan, maupun kontur dari gunung itu sendiri. Demikian juga, walaupun bisa sedikit diabaikan faktor interferensi dengan gelombang lain karena di gunung, tetapi hal ini sebaiknya juga diantisipasi.

Gelombang radio pada frekuensi rendah mempunyai jarak jangkauan atau bandwidth yang lebar walaupun dengan konsumsi daya yang kecil, sebenarnya ini adalah keuntungan, tetapi dalam penelitian ini dengan memperhatikan data dari sensor yang akan dibawa cukup besar, berupa data digital, karakter dan visual yang memiliki kapasitas besar dengan persyaratan realtime, dapat 
dipantau secara online, dapat dialamati dan dapat dimuati sistem keamanan, maka penelitian ini menggunakan frekuensi tinggi dalam orde Giga, yaitu gelombang Wifi $2,4 \mathrm{GHz}$.

Secara singkat konsep perancangan pada penelitian ini adalah melakukan transmisi data digital dan data visual bergerak secara real time dari sebuah jaringan lokal intranet (node sensor di punggung gunung) menuju jaringan internet global (pusat monitoring di daerah yang sudah terjangkau akses internet). Dengan frekuensi tinggi sesuai regulasi yaitu pada frekuensi carrier $2,4 \mathrm{GHz}$ pada daya maksimal yang diijinkan. Untuk itu dipilih modul-modul yang sudah tersedia dan mudah didapatkan dengan tingkat efisien dan efektifitas yang tinggi, yaitu node sensor seismik MEMs, Raspberry Pi $\mathrm{B}+$, dan Bullet2HP Wifi amplifier. Untuk alat penunjangnya digunakan antena grid $2.4 \mathrm{GHz}$, modul panel surya, inverter $\mathrm{DC}$ to $\mathrm{AC}$, dan mikrokontroller ATMEGA8.

\subsection{Komunikasi point to multipoint menggunakan telemetri Wifi.}

Konsep perancangan seperti Gambar 1 menawarkan proses transfer data yang cepat karena telemetrinya menggunakan sinyal Wifi $2.4 \mathrm{GHz}$, jarak jangkau yang lebih jauh dari telemetri radio modem $413 \mathrm{MHz}$. Proses enkripsi data lebih mudah, hemat perangkat keras komunikasi karena merupakan sistem point to multipoint.

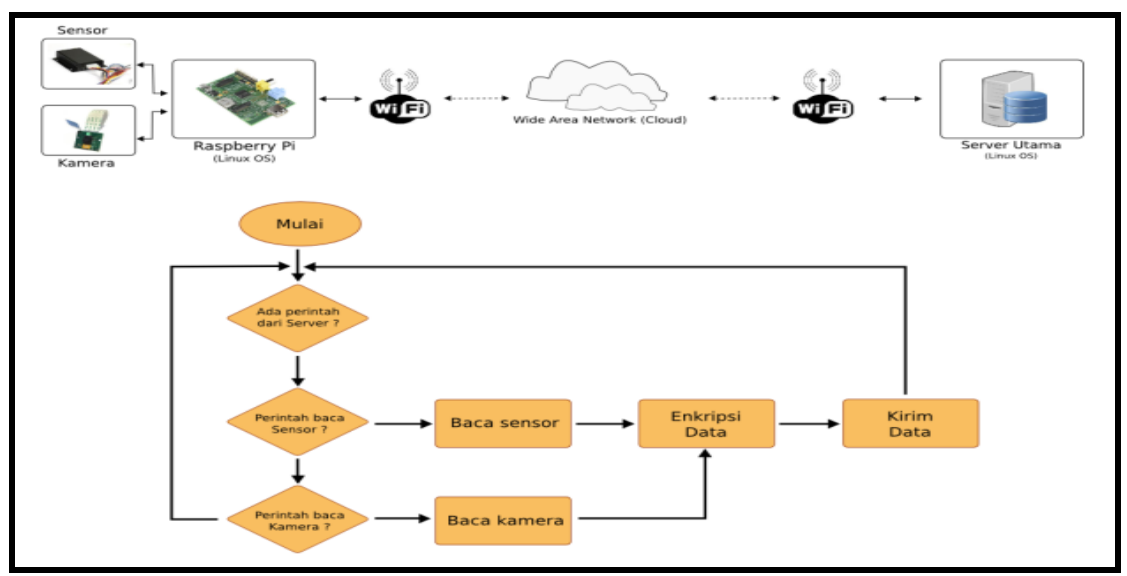

Gambar 1. Diagram alir perancangan sistem

Jaringan 4 sensor yang dinyatakan sebagai 4 point melakukan komunikasi teralamati kepada satu transceiver multipoint. Komunikasi Wifi yang sebelah kiri atau dari mini pc raspberry (1unit sensor) adalah dalam lingkup intranet/lokal. Sementara dari WAN akan terhubung dengan internet global menuju server utama seperti yang ditunjukkan pada Gambar 2.

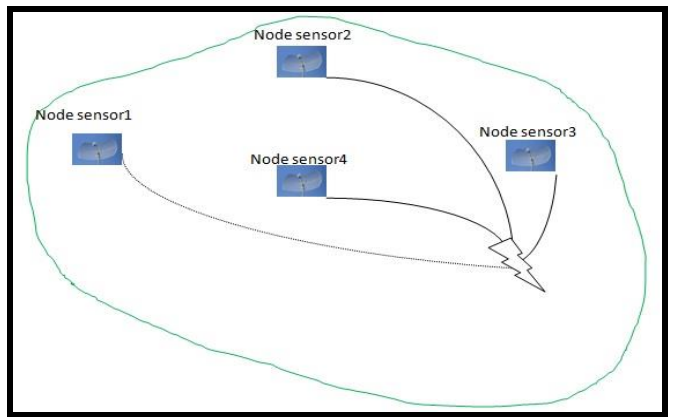

Gambar 2. Pemasangan WSN seismik secara point to multipoint
Blok diagram perangkat keras pada node sensor dapat dlihat pada Gambar 3 . Penempatan node sensor adalah di sekeliling punggung gunung, diusahakan untuk memiliki Line of Sight yang baik dengan antena server. Walaupun secara teoritis seperti dijelaskan sebelumnya bahwa obstacle/penghalang bisa dijadikan sebagai media pemantul.

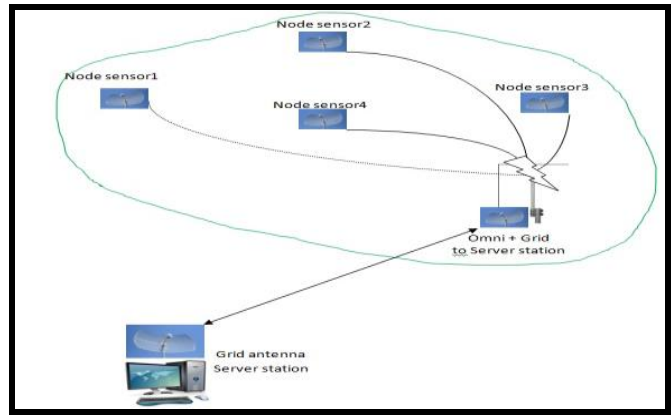

Gambar 3. Blok perangkat keras node sensor 


\subsection{Aplikasi lapangan konfigurasi point to multipoint}

Solusi terburuk dari konfigurasi point to multipoint adalah menambahkan beberapa titik sebagai repeater, atau dipasang juga sebuah antena omni multidirectional lagi di ser punggung gunung juga, dan kemudian sinyal dari antena omni pengumpul di punggung gunung dipancarkan dengan antena directional (grid) ke server pusat secara point to point dengan antena grid yang saling berhadap hadapan Line of Sight seperti pada Gambar 4.

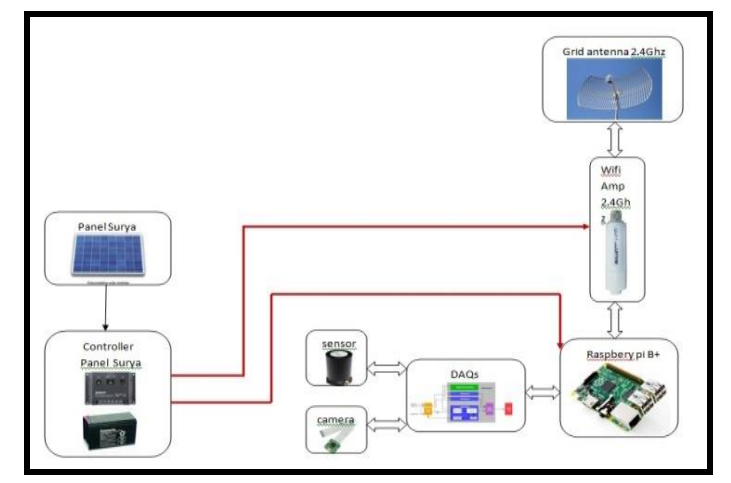

Gambar 4. Mode WSN seismik point to multipoint

\subsection{Langkah pengerjaan}

Langkah pengerjaan disusun berurutan mulai dari pembuatan modul hardware untuk node sensor, meliputi sensor seismik, DAQ raspberry pi $\mathrm{B}+$. Langkah pertama adalah menyusun modul-modul antena omni, Bullet2HP Wifi amplifier, dan PC desktop. Kedua adalah melakukan pengesetan alamat server dan proses enkripsi.

\subsubsection{Rancangan dan uji node sensor}

Sensor accelerometer adalah sensor yang digunakan untuk mengukur getaran berdasarkan nilai percepatan gravitasi bumi yang diterima oleh sensor. Jenis sensor ini adalah jenis semikonduktor yang terdiri dari 3 arah pengukuran yaitu $\mathrm{X}, \mathrm{Y}$, dan $\mathrm{Z}$, sehingga bisa digunakan untuk mengamati getaran (seismic) dengan frekwensi $>1 \mathrm{~Hz}$ dari segala arah. Satuan ukur sensor ini adalah g (gaya gravitasi), dimana akan bernilai $1 \mathrm{~g}$ tatkala benda diam tegak lurus terhadap pusat bumi.
Nilai positif menunjukkan adanya percepatan melawan gravitasi, dan nilai negatif menunjukkan percepatan benda jatuh searah dengan vektor gravitasi (Novianta \& Setyaningsih, 2015)

Output dari sensor seismik adalah output TTL (Transistor-Transistor-Logic) dengan range tegangan 0 - 5 volt DC. Output dari sensor seismik ini diumpankan ke modul DAQs yang berbasis mikrokontroller PIC sebagai pengumpul data dan jembatan menuju raspberry pi $\mathrm{B}+$. Output dari DAQs berupa TTL UART yang akan diproses selanjutnya oleh raspberry pi $\mathrm{B}+$ untuk kemudian di umpankan ke modul Wifi Bullet2HP yang selanjutnya akan di transmisikan melalui antena grid 2,4GHz. Dengan adanya pembagian tugas ini, modul-modul tersebut akan ringan kerjanya.

Software pada Raspberry pi $\mathrm{B}+$ fungsinya adalah untuk membuat Raspberry $p i$ $\mathrm{B}+$ bekerja pada mode idle. Pengesetan komunikasi UART antara DAQs dan Raspberry. Pengesetan komunikasi dengan server, salah satunya adalah pengalamatan node sensor.

Setelah perancangan hardware dan software, maka dilakukan pengujian, yaitu:

1. Uji komunikasi UART data antara modul sensor seismic - DAQS -Raspberry.

2. Uji konektivitas antara Raspberry pi B+ dengan modul Wifi Bullet2HP, contohnya adalah alamat Modul mini pc Raspberry pi $\mathrm{B}+$ sudah bisa terhubung secara nirkabel dengan laptop/PC.

3. Pengukuran daya yang digunakan oleh semua sistem pada node sensor dengan menggunakan digital wattmeter.

\subsubsection{Pengujian lapangan}

Pengujian lapangan ditujukan untuk mengetahui sejauh mana performa sistem komunikasi yang sudah di rancang pada kondisi alam pegunungan yang sebenarnya, yaitu mengetahui jarak maksimal pancaran sinyal transmisi, pengaruh cuaca, dan efek penempatan tiap titik dari pengaruh halangan alami. Skema komunikasi antar modul dalam jaringan sensor nirkabel seperti ditunjukkan pada Gambar 5. 


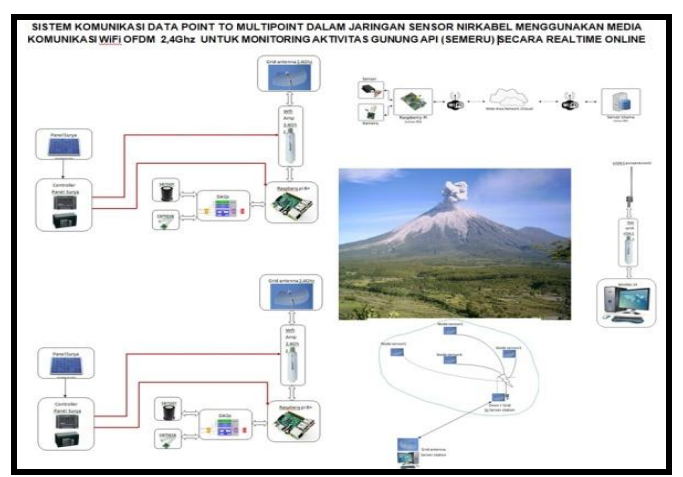

Gambar 5. Sistem komunikasi dalam jaringan sensor nirkabel

\section{HASIL DAN PEMBAHASAN}

Dari hasil perancangan, dan pengujian alat. Sistem telemetri Wifiuntuk monitoring data seismik gunung api ini bisa bekerja dengan baik. Tetapi pengujian ini dilakukan tidak di lapangan yang sesungguhnya, skema pengujian juga mengalami sedikit modifikasi tanpa mengubah konsep dasarnya. Hal ini terutama untuk mengatasi keterbatasan alat pengujian pada peralatan Wifi amplifier dan akses point.

Jarak jangkau yang dilakukan di pengujian ini maksimal pada jarak $2 \mathrm{~km}$ line of sight, data berupa data sensor dan gambar bergerak bisa diterima dengan baik. Itupun dengan menggunakan pusat pemancar adalah antena omni yang beamwidth-nya melingkar, sehingga kurang maksimal jangkauannya untuk penggunaan point-to-point yang saling berhadapan.

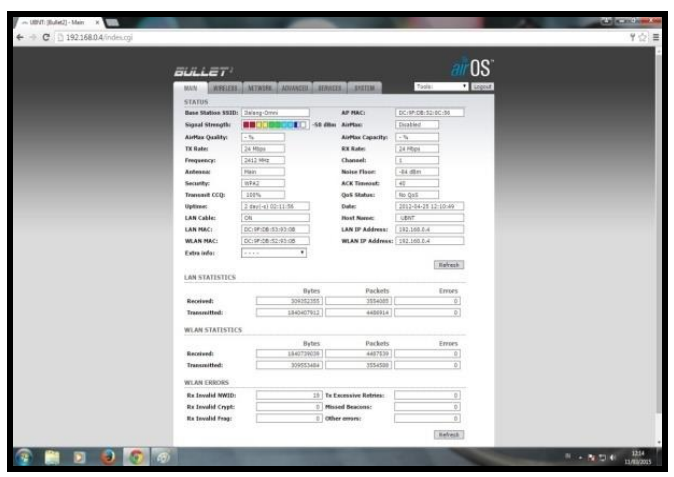

Gambar 6. Hasil pengukuran kekuatan sinyal

Dari Gambar 6 terlihat bahwa pada jarak $1 \mathrm{~km}$ signal strenght yang didapatkan masih cukup tinggi yaitu $-58 \mathrm{dbm}$, noise floor -84 $\mathrm{dbm}$, dan transmit ccq 100\% (tidak terjadi loss data transmision). Jadi pengujian tidak dapat dilakukan pada daya maksimal supaya diperoleh signal strenght yang lebih tinggi lagi.
Data visual yang diharapkan real time tetapi tidak sepenuhnya real time, karena dibuat ada delay 5detik, karena ketika dicoba pada delay yang pendek sekali agar gambar berjalan lebih cepat, mesin/processor utama pada raspberry mengalami over heat, jadi tidak sesuai untuk pemakaian terus menerus dalam jangka waktu yang lama

Sistem node pada penelitian ini menggunakan Raspberry Pi sebagai pengatur utama sistem. Sensor MMA7631 yang berfungsi untuk mendeteksi akselerasi grafitasi dihubungkan dengan Raspberry Pi melalui port GPIO.

Mode jaringan pada Bullet dapat dikonfigurasi sebagai Bridge atau AccessPoint. Pada mode bridge, sistem jaringan pada Raspberry $P i$ dan Bullet dijadikan satu, sehingga Raspberry $P i$ terhubung secara langsung dengan sistem jaringan nirkabel. Pada mode access point, Raspberry $P i$ berfungsi sebagai client.Sehingga untuk terhubung ke jaringan nirkabel, harus melalui jaringan pada Bullet terlebih dahulu.

\subsection{Desain perancangan}

Desain sistem telemetri yang digunakan adalah dengan beberapa node yang terhubung pada access point. Karena menggunakan sistem jaringan komputer, maka tiap node dapat dialamati, masing-masing node memiliki IP Address yang berbeda, seperti yang ditunjukkan pada Gambar 7.

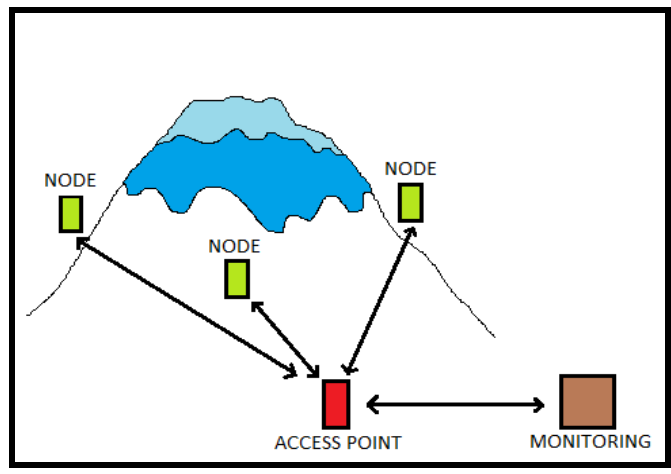

Gambar 7. Jaringan node sensor dan monitoring

Bullet yang terdapat pada node, dikonfigurasi sebagai bridge, sehingga Bullet berfungsi sebagai antena nirkabel dari Raspberry Pi. Pada mode bridge, dua jaringan digabungkan menjadi satu, yaitu jaringan Raspberry Pi dan jaringan dari Bullet. Dengan 
mode ini, Raspberry $P i$ mendapatkan akses langsung pada jaringan nirkabel, tanpa melalui sistem jaringan internal pada Bullet, sehingga alamat pada Raspberry $P i$ dapat dipanggil langsung dari sistem Access Point. Hal ini menjadikan sistem monitoring dapat memanggil langsung alamat tiap node.

Pada Access Point, mode jaringan bullet dikonfigurasi sebagai Access Point. Dengan mode ini, bullet berfungsi untuk mengatur lalu lintas jaringan nirkabel. Trafik data akan diteruskan antara sistem monitoring dan node sesuai alamat jaringannya masing-masing. Sistem monitoring dihubungkan secara nirkabel melalui Access Point, sehingga sistem monitoring dapat terhubung dengan tiap node dengan memanggil IP Address node yang akan dimonitor.

\subsection{Desain pada pengujian}

Pada pengujian, karena hanya menggunakan satu node, maka desain dapat disederhanakan. Node diberlakukan juga sebagai access point. Sistem monitoring disambungkan secara nirkabel dengan node. Pada desain ini, ubahan yang dilakukan adalah model jaringan pada Bullet di sistem node, dikonfigurasi sebagai access point.Rangkaian pengujian dapat dilihat pada Gambar 8 . Raspberry Pi berlaku sebagai client dari Bullet yang terhubung langsung melalui kabel UTP pada tiap port RJ45 kedua perangkat, sedangkan Sistem monitoring terhubung dengan Bullet melalui nirkabel. Bullet berfungsi untuk mengatur lalu lintas data, dari sistem monitoring, ke Raspberry Pi.Sehingga sistem monitoring dapat menghubungi
Raspberry $P i$ sesuai dengan IP Address yang terkonfigurasi.

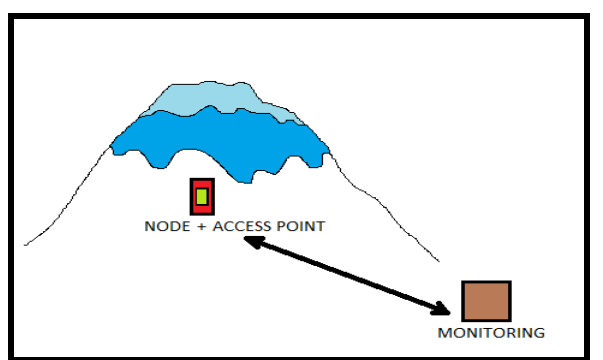

Gambar 8. Modifikasi rangkaian pengujian

\subsection{Penyajian data}

Hasil output dari program yang dibuat berbasis Web Framework CherryPy, dimana data disajikan dalam dua bentuk, yaitu :

a. Dalam bentuk halaman web

b. Dalam bentuk Application Programming Interface (API)

Pada penyajian berbentuk web, maka pengguna cukup mengetik alamat IP Raspberry $P i$ pada browser, baik dari komputer atau dari perangkat mobile (handphone dan tablet). Jika ada permintaan penyajian dalam bentuk halaman web, maka sistem akan mengirimkan halaman web, dimana didalamnya terdapat data lengkap nilai-nilai sensor untuk setiap sumbu sensor. Dalam halaman ini juga disajikan plot data berbentuk grafik yang akan menampilkan data secara real-time seperti yang ditunjukkan pada Gambar 9. Halaman web juga menampilkan hasil gambar yang diambil oleh sensor kamera , sebagai contoh http://192.168.1.9.

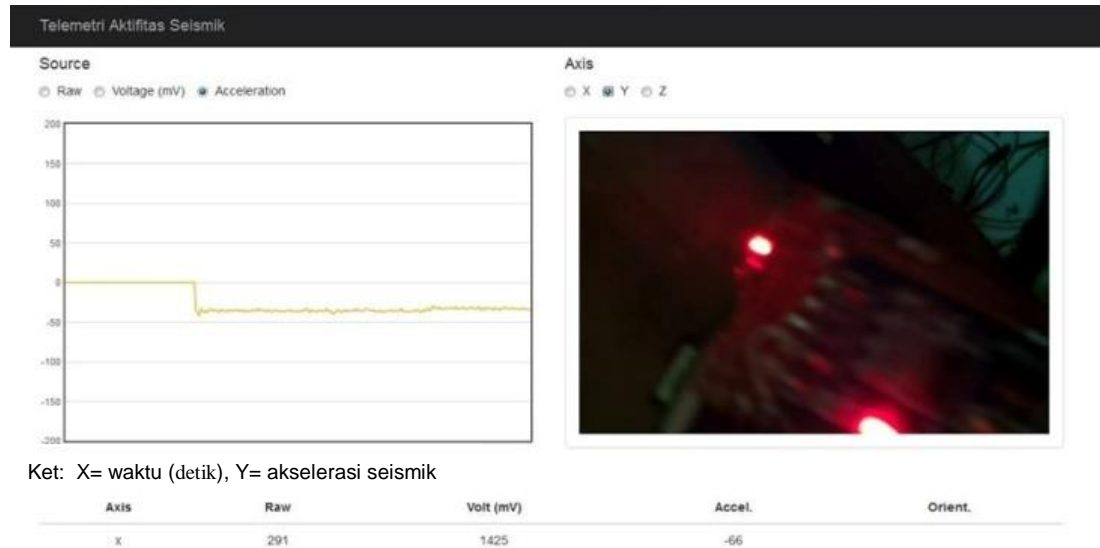

Gambar 9. Hasil pengujian sensor seismik dan kondisi visual pada gunung api 
Penyajian berbentuk API, merupakan penyajian dalam bentuk data mentah, yang dapat dimanfaatkan oleh aplikasi lain. Untuk mendapatkan data mentah tersebut, aplikasi dapat melakukan pemanggilan http request sebagai contoh http://192.168.1.9/sensor, sedangkan permintaan gambar dapat menggunakan cara yang sama sebagai contoh http://192.168.1.9/image.jpg. Diagram alir penyajian data dapat dilihat pada Gambar 10.

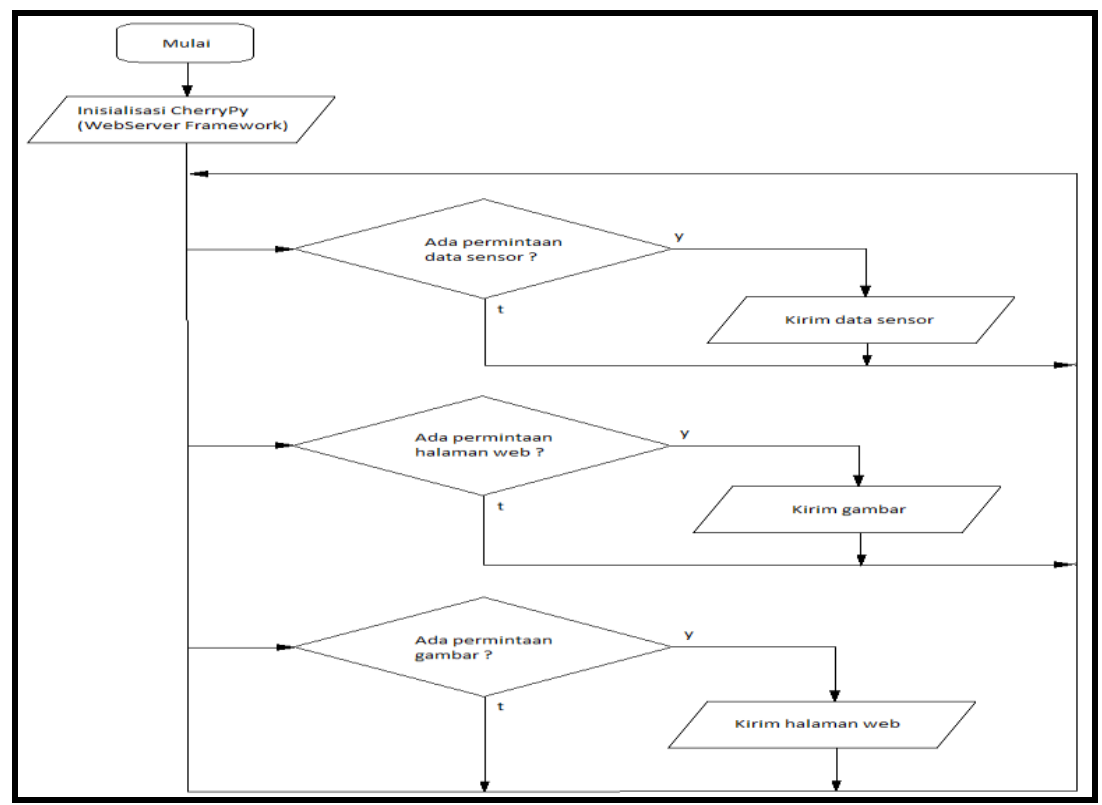

Gambar 10.Diagram alir penyajian data

\section{PENUTUP}

\subsection{Kesimpulan}

Sistem komunikasi telemetri jaringan sensor terpadu untuk wilayah geografis gunung berapi dengan kelebihan sistem dapat memberikan informasi parameter fisik dari kondisi gunung berapi yang akurat real time, online, kecepatan transmisi yang tinggi, mudah diduplikasi, fleksibilitas untuk penambahan sensor yang lain tinggi sebagai satu bagian untuk pengambilan keputusan penentuan status gunung berapi.

Penggabungan data sensor seismik dan data visual di ser gunung dapat dilakukan sekaligus, walaupun untuk data visualnya masih dibatasi tidak benar-benar real time, karena harus dilakukan delay supaya modul yang digunakan sebagai pemrosesnya dapat dipakai dalam waktu yang lama secara terus menerus. Data visual yang dihasilkan oleh kamera Raspberry Pi masih mempunyai delay 5 detik. Hal ini dilakukan karena jika dibuat real time per detik, mesin dari Raspberry $\mathrm{Pi}$ menjadi panas.

\subsection{Saran}

Dalam penelitian ini perlu dicarikan solusi untuk membuat mesin Raspberry Pi agar mampu membaca data secara real time untuk kamera resolusi tinggi tanpa perlu dilakukan delay waktu.

\section{DAFTAR PUSTAKA}

[1] Maryanto, S., Santoso, D.R., Mulyana, I., \& Hendrasto, M., 2011. Fractal and Chaos Properties of Explossion Earthquakes Followed By Harmonic Tremor at Semeru Volcano, East Java, Indonesia, IJSER Journal, Vol. 2, Issue 7, pp. 1-7.

[2] Novianta, M.A., \& Setyningsih, E., 2015. Rancang Bangun Sistem Deteksi Dini Gempa Bumi Berdasarkan Fluktuasi Medan Magnet Menggunakan Sensor MEMS. Techno, Vol. 16 No. 1, pp. 35-44.

[3] Santoso, D.R., Maryanto, S., \& Purnama, R. 2012. Development of Internet Based Instrumentation System for Real Time Visual Monitoring of Volcano. IJERD Journal, Vol. 4, Issue 12, pp. 23-29.

[4] Santoso, D.R., Maryanto, S., \& Wardoyo, A.Y.P. $2012^{\mathrm{b}}$. Development of Simple and Low Cost Instrumentation for Real Time Volcano Monitoring. IJAET Journal, Vol. 2 , issue 1 , pp. $432-542$

[5] Scarpa, R., \& Tilling, R.I., 1996. Monitoring And Mitigation of Volcano Hazard. Berlin, Germany, Springer-Verlag 